\title{
GENE EXPRESSION ANALYSIS IN CALCIFIC TENDINOPATHY OF THE ROTATOR CUFF
}

\author{
Francesco Oliva ${ }^{1}$, Donatella Barisani ${ }^{2}$, Andrea Grasso ${ }^{3}$ and Nicola Maffulli** \\ ${ }^{1}$ Department of Trauma and Orthopaedic Surgery, University of Rome "Tor Vergata", School of Medicine, Rome, \\ Italy \\ ${ }^{2}$ Department of Experimental Medicine, University of Milano-Bicocca, Monza, Milan, Italy \\ ${ }^{3}$ Department of Shoulder Surgery, Villa Valeria Hospital, Rome, Italy \\ ${ }^{4}$ Centre for Sports and Exercise Medicine Queen Mary University of London, Barts and The London School of \\ Medicine and Dentistry, Mile End Hospital, London, U.K.
}

\begin{abstract}
We evaluated the expression of several genes involved in tissue remodelling and bone development in patients with calcific tendinopathy of the rotator cuff. Biopsies from calcified and non-calcified areas were obtained from 10 patients ( 8 women and 2 men; average age: 55 years; range: 40-68) with calcific tendinopathy of the rotator cuff. To evaluate the expression of selected genes, RNA extraction, cDNA synthesis and quantitative polymerase chain reaction (PCR) were performed. A significantly increased expression of tissue transglutaminase (tTG) 2 and its substrate, osteopontin, was detected in the calcific areas compared to the levels observed in the normal tissue from the same subject with calcific tendinopathy, whereas a modest increase was observed for catepsin $\mathrm{K}$. There was also a significant decrease in mRNA expression of Bone Morphogenetic Protein (BMP)4 and BMP6 in the calcific area. BMP-2, collagen $V$ and vascular endothelial growth factor (VEGF) did not show significant differences. Collagen $\mathrm{X}$ and matrix metalloproteinase (MMP)-9 were not detectable. A variation in expression of these genes could be characteristic of this form tendinopathy, since an increased level of these genes has not been detected in other forms of tendon lesions.
\end{abstract}

Keywords: Calcific tendinopathy, rotator cuff, genetic expression.

\footnotetext{
*Address for correspondence

Nicola Maffulli

Centre for Sports and Exercise Medicine

Queen Mary University of London, Barts

and The London School of Medicine and Dentistry

Mile End Hospital, 275 Bancroft Road,

London E1 4DG, U.K.

E-mail: n.maffulli@qmul.ac.uk
}

\section{Introduction}

Calcific tendinopathy of the tendons of the rotator cuff is common in Caucasian populations, with a reported prevalence varying from $2.7 \%$ to $22 \%$, mostly affecting women between 30 and 50 years (Bosworth, 1941; Lippmann, 1961; Welfling et al. 1965; Refior et al. 1987; Uthoff, 1997). In $10 \%$ of patients, the condition is bilateral and it usually involves the supraspinatus tendon (Bosworth, 1941; De Palma and Kruper, 1961; Ark et al., 1992).

The pathogenesis of calcific tendinopathy is still debated, and two different theories have been developed: in the first one, degeneration of tendon fibres is regarded as the first step, followed by the development of calcium deposits (Steinbrocker, 1972). In the second one, Uhthoff and co-workers hypothesised that a favourable environment permits an active process of cell-mediated calcification, usually followed by spontaneous phagocytic resorption (Uhthoff and Loehr, 1997). However, the reason of the association of calcium deposition with the process of tendon degeneration is still unknown (Uhthoff and Loehr, 1997).

Recently, Harvie et al. noted, in a retrospective cohort study of 102 consecutive patients with calcific tendinopathy, a significantly higher prevalence of thyroid and oestrogen hormones metabolism alterations compared to a control population. When patients were classified according to the presence or absence of endocrine disorders, no significant differences between cohorts for mean pain scores, time off work, presence of bilateral calcific tendinopathy, or dominant arm involvement were observed (Harvie et al., 2007). However, earlier onset of the symptoms, longer natural history and a higher proportion of patients undergoing surgery were evident in patients with associated endocrine disorders, suggesting a possible classification of the disease in idiopathic and endocrine-related forms (Harvie et al., 2007).

Achilles tendinopathy (Mokone et al., 2006), rotator cuff tendinopathy (Gwilym et al., 2009) and tears of the quadriceps tendon (Longo et al., 2010) may have a genetic component. However, specific genes have not been associated with rotator cuff injuries yet (September et al., 2007).

Attempts to reproduce the peculiar tendon environment of calcific tendinopathy have employed macrophages and synthetic apatite crystals and/or natural apatites (Cheung et al., 1981). This approach might help to understand 
how calcified material can be reabsorbed, but it does not explain fully the pathological processes involved in the development of the lesion.

Gene expression studies could provide some further insights in calcific tendinopathy, but few data are currently available on this disorder (Sweet and Green, 1981; Zaka et al. 2006). On the contrary, studies performed in overuse injuries of the supraspinatus tendon evidenced increased expression of cartilage-specific genes and down-regulation of tendon specific genes. These changes suggest that the phenotype of the supraspinatus tendon becomes more cartilage-like as a result of overuse (Archambault et al., 2007). However, in a rat model, just 2 weeks of rest are often sufficient to recover from the molecular and biochemical effects of 2 and 4 weeks of overuse (Jelinsky et al., 2008).

Many proteins could be involved in calcification or tendon rearrangement processes, playing different roles in the various phases of generation of calcification and resorption. Among the possible candidates there are Bone Morphogenetic Proteins (BMPs) and transglutaminases (TGs). BMPs regulate calcification processes in the bone (Rider and Mulloy, 2010), but their role in tendon repair has not been completely clarified yet. The major function of transglutaminases is the covalent crosslinking of one protein chain via a glutamine residue to a lysine residue of another protein chain in a reaction termed transamidation (Lorand and Graham 2003). Transglutaminases are expressed in almost all mammalian tissues, and their importance has been highlighted in wound healing and tissue repair, bone development and apoptosis (Johnson et al., 2003; Nurminskaya et al. 2003; Iismaa et al., 2009). Another possible player is osteopontin, a protein produced by osteoblasts that was shown to be involved in the anchoring of osteoclasts to the mineral of bone matrix (Reinholt et al., 1990). Upregulation of osteopontin is associated with chondrocyte terminal differentiation (Franzen et al., 1989), and a role of osteopontin in modulating crystal nucleation and growth in mineralizing tissues has been hypothesised. Osteopontin has been observed in cells surrounding tendon calcifications, although its role has not been further clarified (Halverson, 2003).

Different collagen types could also play a role in the generation of calcification; type $\mathrm{V}$ collagen is a major component of the non-fibrous collagen of blood vessels, and increased amounts of type $\mathrm{V}$ collagen have been detected in association with the presence of many new blood vessels in the granulation tissue at 10 and $20 \mathrm{~d}$ during murine tendon healing. The authors also hypothesised that ectopic ossification of murine healing tendons may be linked to reduced amounts of type $\mathrm{V}$ collagen (Brown et al., 1986). On the other hand, type $X$ collagen is a short chain collagen which has been associated with calcific cartilage and/or the expression of the hypertrophic chondrocyte phenotype (Stephens et al., 1992).

Extracellular matrix can also be affected by the activity of metalloproteinases (MMPs), and significant expression of the MMP9 has been detected during rotator cuff and Achilles tendon tears (Karousou et al., 2008; Lakemeier et al., 2011). Moreover MMP-9 was the gelatinase required for the removal of denatured collagen fragments and mediated by the vascular invasion of hypertrophic cartilage callus in developing murine long bones (Colnot et al., 2003).

VEGF has the potential to stimulate the expression of matrix metalloproteinases and inhibit the expression of tissue inhibitors of matrix metalloproteinases (TIMP) in various cell types (e.g., endothelial cells, fibroblasts, chondrocytes), and therefore this cytokine may play a significant role in the pathogenetic processes of degenerative tendon disease (Pufe et al., 2005).

We thus evaluated the expression of several genes involved in tissue remodelling and bone development in patients with calcific tendinopathy of the rotator cuff, comparing in particular the calcific area with the surrounding macroscopically normal tendon.

\section{Materials and Methods}

\section{Patient selection}

Ten patients ( 8 women and 2 men; average age: 55 years; range: $40-68$ ), with symptomatic calcific tendinopathy for more than 6 months and who had failed conservative management which included oral non-opiate analgesics, non-steroidal anti-inflammatory drugs, and physical therapy, underwent routine arthroscopic removal of the calcified deposits performed at our institution by the senior surgeons. Biopsies were also taken in all these patients from macroscopically healthy areas of the same tendons.

Patients included in this investigation showed at anterior-posterior, lateral and outlet plain radiographs evidence of calcific deposits in the subacromial space. Exclusion criteria were the presence of calcific deposits

Table 1. Primers employed for quantitative PCR using the Sybr Green technique.

\begin{tabular}{|l|l|l|l|}
\hline Analysed Gene & Forward Primer & Reverse Primer & $\begin{array}{l}\text { A n n e a l i n g } \\
\text { temperature }\end{array}$ \\
\hline tTG2 & AAGAGGAGCGGCAGGAGTAT & AGGAACTTGGGGTTGACATC & $58^{\circ} \mathrm{C}$ \\
\hline Collagen X & TTTTACGCTGAACGATACCA & TACCTTGCTCTCCTCTTACT & $56^{\circ} \mathrm{C}$ \\
\hline Collagen V & AACTTGCCTGATGGAATAAC & TGGATACCCTGCTCGTTGT & $56^{\circ} \mathrm{C}$ \\
\hline VEGF & ATCCTGTGTGCCCCTGAT & TCTTGTCTTGCTCTATCTTTC & $56^{\circ} \mathrm{C}$ \\
\hline MMP9 & TGACAGCGACAAGAAGTGG & TGTGGTGGTGGTTGGAGG & $58^{\circ} \mathrm{C}$ \\
\hline Osteopontin & CAGTGATTTGCTTTTGCCTC & AGTCATTGGTTTCTTCAGAG & $59^{\circ} \mathrm{C}$ \\
\hline Osteonectin & CAGAGGAAACCGAAGAGGAG & AAAGAAGTGGCAGGAAGAGT & $59^{\circ} \mathrm{C}$ \\
\hline Cathepsin K & TAGTGGATTGTGTGTCTGAG & CCTTGCCTGTTGGGTTGTA & $56^{\circ} \mathrm{C}$ \\
\hline
\end{tabular}




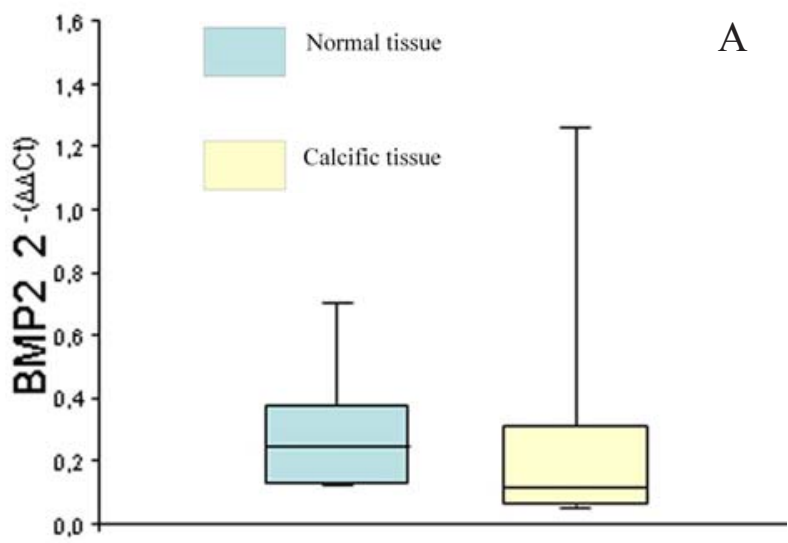

B

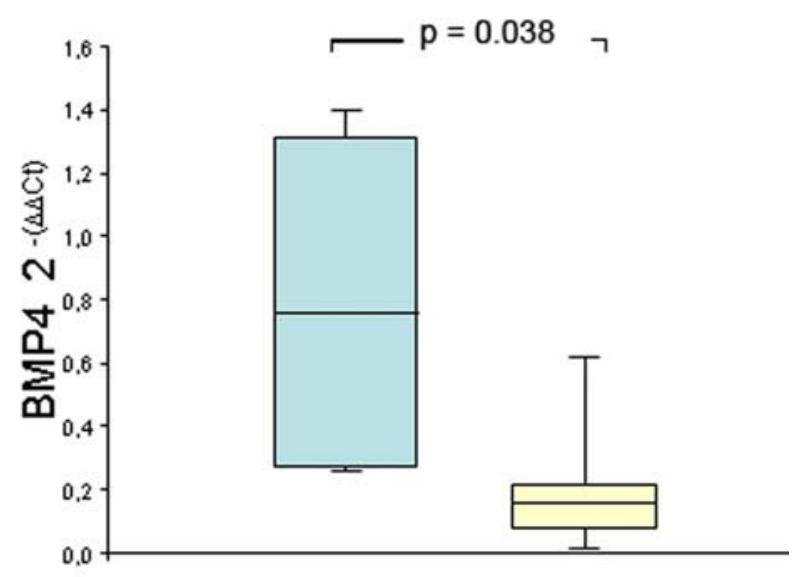

C

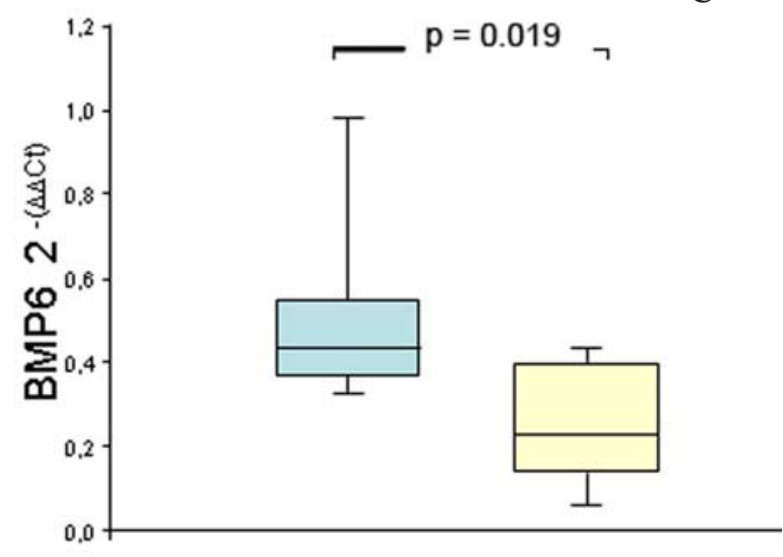

Fig. 1. Bone Morphogenetic Proteins (BMPs) mRNA expression in macroscopically normal or calcific tissue obtained from patients with calcific tendinopathy. Panel (A) BMP2; (B) BMP4; (C) BMP6. mRNA levels for BMPs were determined by quantitative PCR (Taqman assay) and normalised for the amount of GAPDH present in each sample. The relative level of expression in each macroscopically normal or calcific tissue obtained from patients was compared to cDNA obtained by retrotranscription of a pool of RNA obtained from the control subjects, to which a value of 1 was arbitrarily assigned. Values were compared using paired Student's $t$-test $(n=10)$.

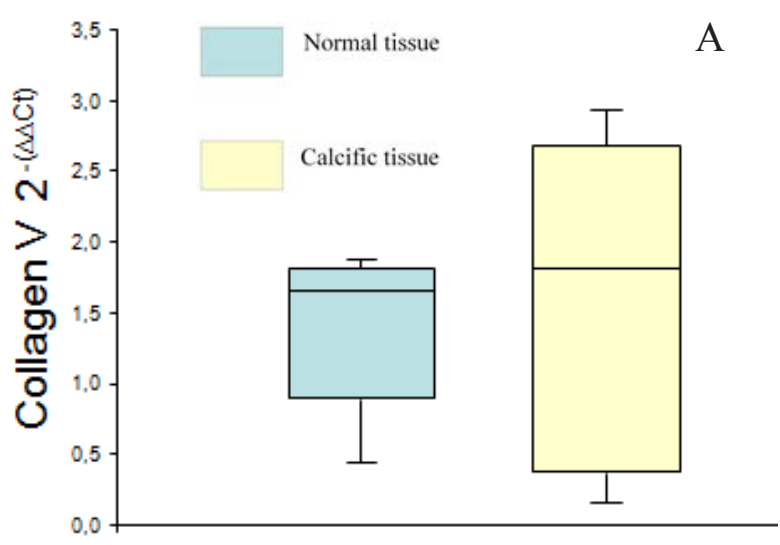

B
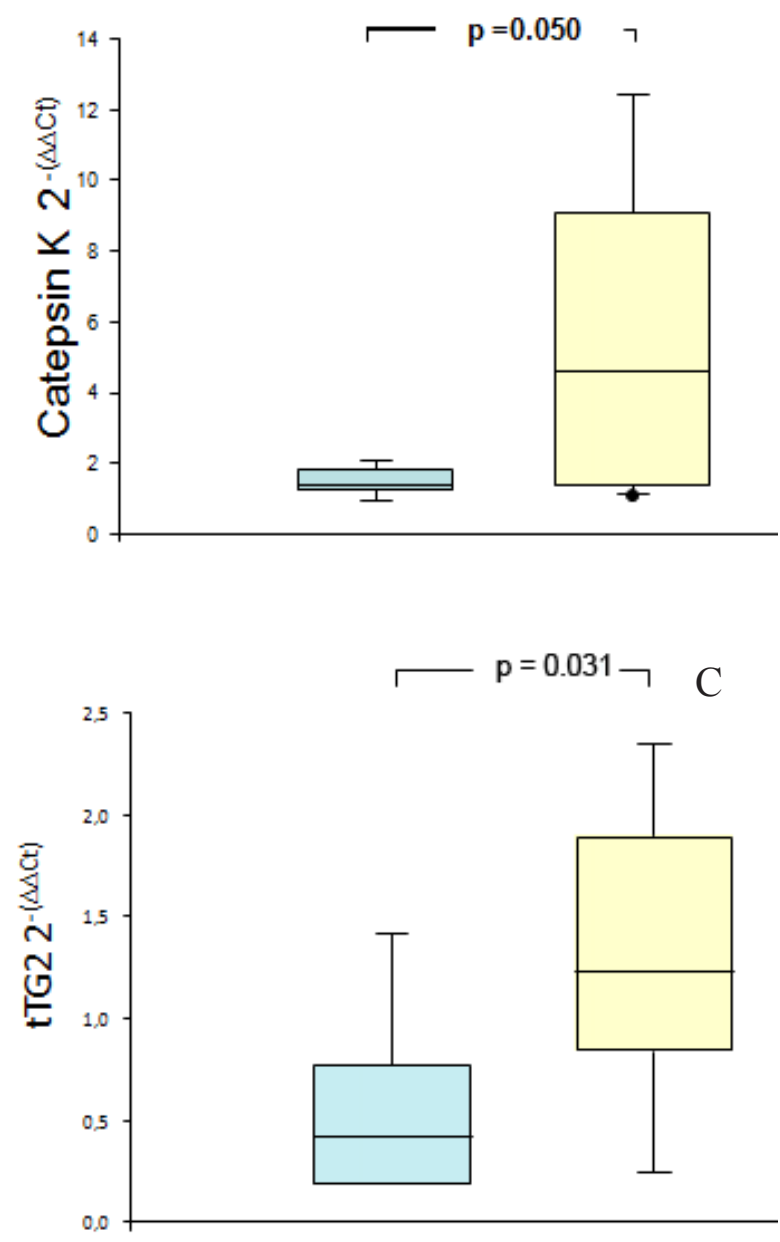

Fig. 2. mRNA expression of genes related to extracellular matrix in macroscopically normal or calcific tissue obtained from patients with calcific tendinopathy. Panel (A) Collagen $\mathrm{V}$; (B) Cathepsin K; (C) tissue Transglutaminase 2 (tTG2). mRNA levels for the various genes were determined by quantitative PCR (Sybr Green) and normalised for the amount of GAPDH present in each sample. The relative level of expression in each macroscopically normal or calcific tissue sample obtained from patients was compared to cDNA obtained by retrotranscription of a pool of RNA obtained from the control subjects, to which a value of 1 was arbitrarily assigned. Values were compared using paired Student's $t$-test $(n=10)$. 
which from the tendon extended into the insertion of the rotator cuff on the humeral head, and the detection at arthroscopy of other shoulder conditions. Moreover, patients with endocrinological or gynaecological diseases were excluded.

To obtain an external reference value for quantitative polymerase chain reaction (PCR) analysis, we used biopsies from intact supraspinatus tendons after arthroscopic stabilisation of shoulder instability from 10 different patients (5 women and 5 men; average age: 33; range 27-40). All patients gave written informed consent before enrolment in the study. All the procedures described in the present study received ethical approval from the Ethics Committee of the University of Rome.

\section{Biopsy processing, RNA extraction and cDNA synthesis}

Biopsies were obtained during surgery both in control patients undergoing surgery for shoulder instability and in patients with calcific tendinopathy of the rotator cuff and in apparently healthy area, transferred to sterile microtubes, snap-frozen in liquid nitrogen, and preserved at $-80{ }^{\circ} \mathrm{C}$ until processing.

RNA from normal tendons and calcific areas, as well as from controls, was extracted homogenising the biopsy in the presence of TRIzol (Invitrogen, Grand Island, NY, USA) using a micro manual homogeniser, and then continuing the procedure according to the manufacturer's protocol. RNA was quantified by spectrophotometry, and its integrity assessed by non-denaturing agarose gel. Two micrograms of total RNA were used as template for reverse transcription, performed using the High Capacity cDNA Archive kit which employs random primer hexamer (Applera, Foster City, CA, USA), according to manufacturer's protocol.

\section{Real-time quantitative PCR}

mRNA levels of Bone Morphogenetic Proteins 2, 4 and 6 (BMP2, BMP4 and BMP6) were evaluated by real time PCR (qPCR) on an ABI 7900HT (Applera) using the Assays-on-Demand Gene Expression Products (Applera) according to the manufacturer's protocol.

Quantification of tissue transglutaminase 2 (tTG2), collagen X, collagen V, VEGF, Matrix Metalloprotease 9 (MMP9), osteopontin, osteonectin, catepsin $\mathrm{K}$ was performed using the Sybr green method (Logan et al., 2009). Primers were designed spanning an intron-exon junction, and their sequences are reported in Table 1.

For each PCR reaction, $15 \mathrm{ng}$ of cDNA were used as template. All analyses were carried out in triplicate. Results showing a discrepancy greater than 0.3 cycle between the samples were excluded.

Relative quantities present in each sample were assessed using the $2^{-(\Delta \Delta \mathrm{cT})}$ method; the values obtained for each gene were normalised on a housekeeping gene (GAPDH) to correct for possible differences in the amount added to each PCR reaction. All normalised values were compared to an external control value obtained using cDNA obtained by retrotranscription of a pool of RNA obtained from the biopsies of the 10 patients undergoing
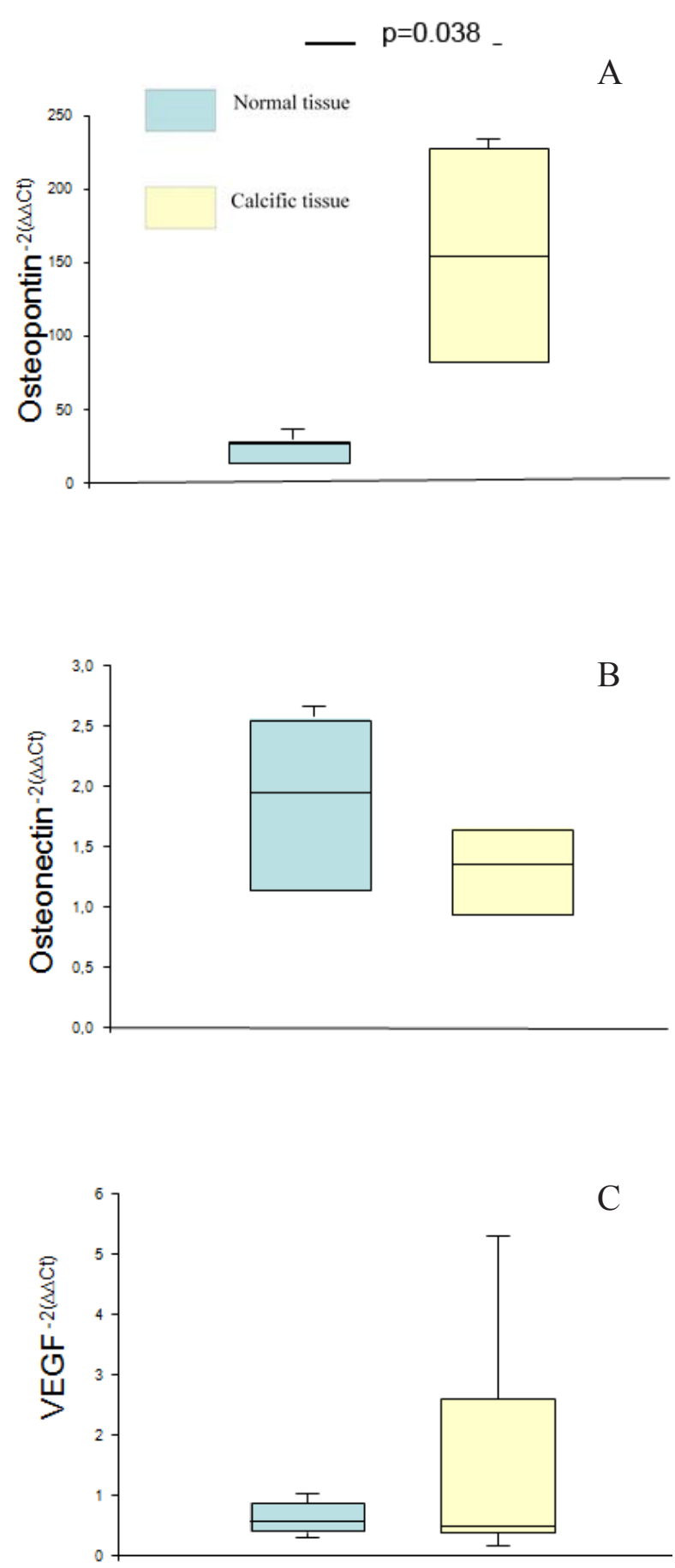

Fig. 3. mRNA expression of genes involved in matrix rearrangement in normal and calcific tissue obtained from patients with calcific tendinopathy. Panel (A) Osteopontin; (B) Osteonectin; (C) VEGF. mRNA levels for the various genes were determined by quantitative PCR (Sybr Green) and normalised for the amount of GAPDH present in each sample. The relative level of expression in each macroscopically normal or calcific tissue obtained from patients was compared to cDNA obtained by retrotranscription of a pool of RNA obtained from the control subjects, to which a value of 1 was arbitrarily assigned. Values were compared using paired Student's $t$-test $(n=10)$. 


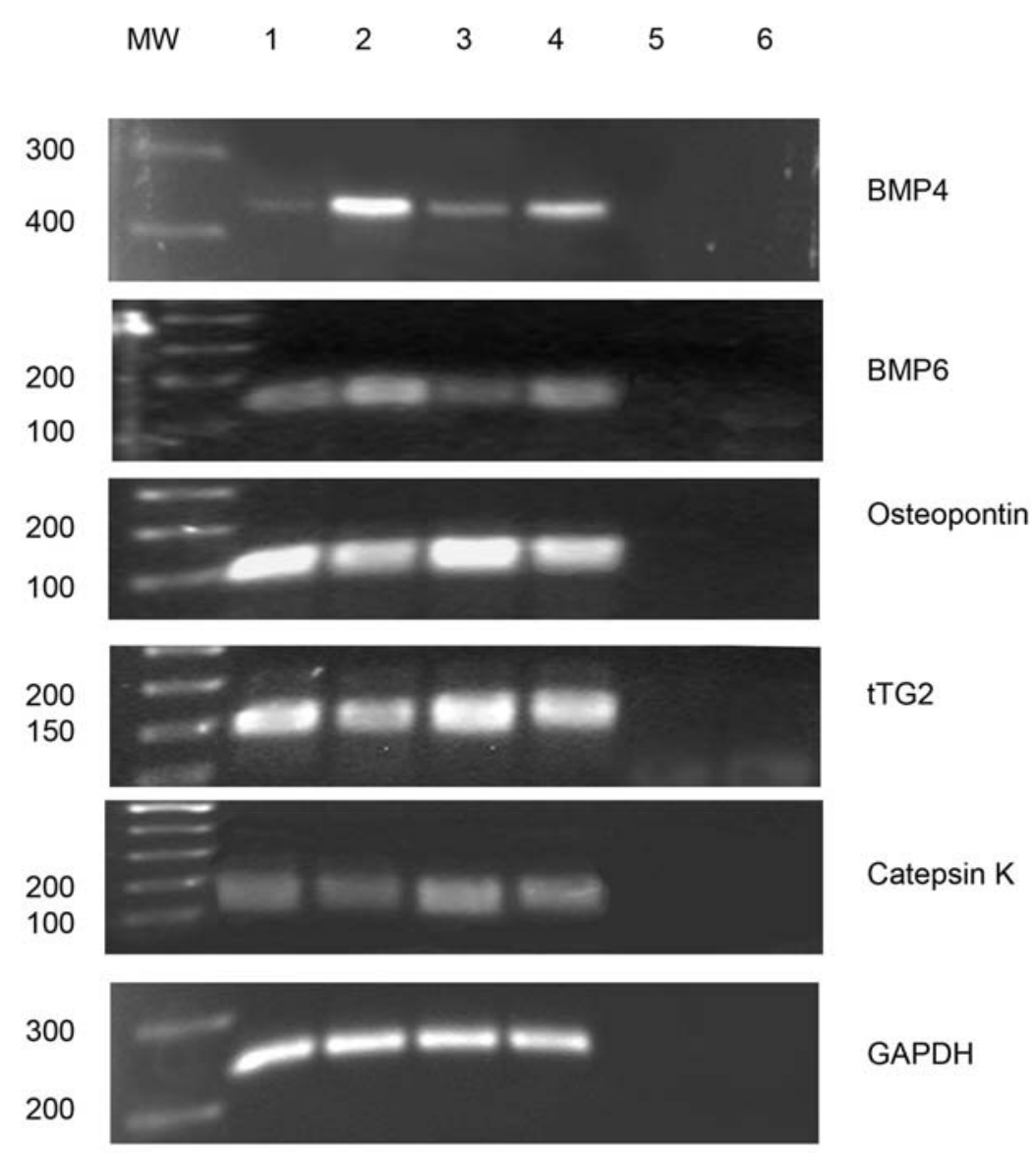

Fig. 4. PCR analysis of differentially expressed genes: Fifteen $\mu \mathrm{L}$ of the PCR reactions were loaded onto a $1 \%$ agarose gel. MW molecular weight markers, lane 1 and 2 cDNA from calcified and normal tissue of patient 3 , lane 3 and 4 cDNA from calcified and normal tissue of patient 6, lane 5 genomic DNA, lane 6 negative control.

surgery for shoulder instability. The external control was arbitrarily assigned a value of 1 .

Data are presented showing the values obtained in the calcific tissue and in the healthy tissue obtained from the same individuals.

Non-retrotranscribed RNAs were included in each amplification plate, and the analysis regarded as valid if the fluorescence intensity in the no-template control was zero.

\section{Statistical analysis}

Statistically significant differences between gene expression values detected in the calcific or non-calcific tissue were analysed by paired Student's $t$-test. Statistical analyses were performed using the SAS System Software (version 9.1) (SAS, Cary, NC, USA).

\section{Results}

To assess whether the presence of calcification within the tendon could be associated with variation in the expression of genes associated with the ossification processes, we firstly evaluated the expression of BMPs. We could not detect any difference in the level of expression of
BMP2 in the calcific tissue as compared to the normal, i.e. non calcific tissue, obtained from the patients with calcific tendinopathy (Fig. 1). On the other hand, the expression of BMP4 and BMP6 mRNA in the calcific area was significantly decreased $(p=0.038$ and $p=0.019$, respectively).

We then analysed the expression of genes related to extracellular matrix, namely collagen $\mathrm{V}$ and $\mathrm{X}$, catepsin $\mathrm{K}$ and tTG2. The mRNA levels of collagen $\mathrm{V}$ were similar in the normal and in the calcific tissue (Fig. 2). Collagen X mRNA was not detectable, neither in the normal nor in the calcific tissue, as was MMP9 mRNA. On the other hand, there was an increased level of cathepsin $\mathrm{K}$ mRNA in the calcific tissue $(p=0.05)$. We also evaluated tTG2 mRNA level, detecting a significant increase of its expression in the calcific areas $(p=0.031)$ (Fig. 2).

Osteopontin and osteonectin can have a role in matrix remodelling, and we detected a significant increase in osteopontin expression in biopsies of the calcific tissue $(p=0.038)$ (Figure 3). On the contrary, no difference was observed in the expression of osteonectin mRNA. VEGF could affect matrix remodelling through its action on vascularisation, but its expression was not different between normal and calcific tissue (Fig. 3). 


\section{Discussion}

The aetiopathogenesis of calcific tendinopathy is still controversial, especially because it remains difficult to clarify the first steps causing this condition and involved in the development of calcifications. These processes require several months, and biopsies of the pathologic cuff tendons are obtained only towards the end of the natural history of this disease, during the resorptive phase (Uhthoff, 1975) and when patients are symptomatic.

Collagen disarray is the main extracellular matrix feature detected around the calcific deposits. This characteristic is similar to what observed in other tendinopathies (Garau et al. 2008; Longo et al., 2008; Sharma and Maffulli, 2008; Zafar et al., 2009), which has prompted to hypothesise that a failed healing response may play a role in the development of calcific tendinopathy. However, why calcific deposits appear, which gene expression changes are associated to calcific tendinopathy, and which cells are involved in its development or resorption still remains to be determined.

Although various proteins could be involved in the different phases, available data have mainly been obtained on the expression of a few genes (Magra and Maffulli, 2007; Magra and Maffulli, 2008). Takeuchi et al. detected osteopontin only in the cells adjacent to the calcified area, identifying, morphologically, two distinct types of osteopontin positive cells, i.e. mononuclear fibroblastic cells and round-shaped mutinuclear cells, present in that area (Takeuchi et al., 2001). The same group also reported the presence of multinucleated TRAP positive giant cells adjacent to the calcium deposits of the rotator cuff tendon, and Cathepsin $\mathrm{K}$ was immunolocalised in this type of cells (Nakase et al., 2000).

Other genes, however, may play an important role in the various phases of calcific tendinopathy, including BMPs, collagens, VEGF, metalloproteases and transglutaminases, whose expression has never been tested in this type of tendon pathology. The possible involvement of these genes is also supported by evidence obtained in other tendon injuries: increased type II collagen expression has been detected in human rotator cuff tendinopathy (Maffulli et al., 2006; Sharma and Maffulli, 2005), and we observed tTG2 and TG2 mRNAs down-regulation in all injured supraspinatus tendons (Oliva et al., 2009).

Here we report an expression analysis study on the expression of various genes usually involved in matrix rearrangement in the healthy or calcific tissue of patients with calcific tendinopathy. We observed an increased expression of Osteopontin, Cathepsin K and tTG2 mRNA in the calcific areas as compared to the level observed in the normal tissue derived from the same subject during surgery.

Osteopontin is a member of the SIBLING (Small Integrin-Binding Ligand N-linked Glycoprotein) family of proteins (Fisher and Fedarko, 2003). SIBLING proteins are secreted matricellular proteins with RGD cell adhesion motif, proteins that also possess the ability to bind to the mineral phase of bones and teeth (Fisher and Fedarko, 2003). Osteopontin is also a substrate for tTG2, since it presents two transglutaminase-reactive glutamines (Q34 and Q36), and treatment of osteopontin with TG2 produces high-molecular weight oligomers with increased collagenbinding capacity (Kaartinen et al., 1999; Higashikawa et al., 2007) In our series of patients with calcific tendinopathy of the rotator cuff, we detected an increased expression of both osteopontin and tTG2 transcripts in the calcified areas, suggesting the presence of a possible common mechanism controlling both the transcription of the enzyme and its substrate. The increased production of both proteins could however be related to different processes according to the tissue in which it takes place. In bone, tTG2 is expressed by osteoblasts (Al-Jallad et al., 2006; Nurminskaya and Kaartinen, 2006), and its crosslinking activity plays a role in the organisation of extracellular matrix. On the contrary, a combined increased expression of tTG2 and osteopontin has been detected in calcified arteries of Gla-deficient mice, a model characterised by ectopic mineral deposition: this phenomenon has been interpreted as an inducible inhibitory mechanism of calcification (Kaartinen et al., 2007). In the same model, osteopontin was expressed close to macrophages, prompting the authors to suggest that osteopontin oligomers created by tTG2 may constitute a scaffold for macrophage adhesion and calcification resorption (Kaartinen et al., 2007). The effect of osteopontin on resorption is further supported by the observation that, in osteopontin $\mathrm{KO}$ mice, administration of recombinant osteopontin induced resorption of ectopic calcifications (Steitz et al., 2002).

The increased expression of osteopontin and tTG2 could thus be compatible with their increased production in the calcific area, probably by osteoclast-like cells involved in the resorptive phase (Nakase et al., 2000). A variation in expression of these genes could be, in theory, a finding characteristic of calcific tendinopathy, since an increased level of these genes has not been detected in other forms of tendon lesions (Maffulli et al., 2006; Archambault et al., 2007; Jelinsky et al., 2007).

We also detected a down-regulation of BMP 4 and 6, a finding possibly related to the clinical stage at which our patients underwent surgery. BMPs can play an important role in cell proliferation and differentiation (Wu et al., 2007), and the reduction in their mRNA levels in the calcific tissue could be associated with a reduced cellularity in this area, or may be one of its causes. Alternatively, the pattern of expression observed in these patients could be due to variations specific of the various phases of the disease, which take place at different time points. In fact, a recent investigation (Yee Lui et al., 2011) analysed the expression of BMPs in the ossified failed tendon healing model of tendinopathy, showing an increased expression of BMP2 in the tendon matrix after 2 weeks, expression almost undetectable afterwards but in the chondroossification sites. On the contrary, BMP4/7 had a bimodal expression, decreasing at 4 and 8 weeks.

Neovascularity has also been postulated as one of the mechanisms involved in the pathogenesis of calcific tendinopathy. However, when we analysed the mRNA levels of VEGF and Collagen V, they were similar in normal and calcific tissue. This finding, by itself, is not 
sufficient to reject this hypothesis, since neovascularisation could be present and play a role only in the first phases of development of the lesion (Cook and Purdam, 2009).

In conclusion, we have identified several genes whose expression is increased in the frankly pathological areas of supraspinatus tendons of patients with calcific tendinopathy. Although our findings paint only a partial picture of this process, they support some of the theories about the pathogenesis of this condition. The role of BMPs in the production of calcific tendinopathy lesions still remains to be elucidated, given their physiological expression in these lesions, although it cannot be excluded that they exerted an initial action, and, once the process initiated, their expression returned to normal. Further investigation, involving also protein studies, will be necessary to further characterise this process, and identify possible future therapeutic targets.

\section{References}

Al-Jallad HF, Nakano Y, Chen JL, McMillan E, Lefebvre C, Kaartinen MT (2006) Transglutaminase activity regulates osteoblast differentiation and matrix mineralization in MC3T3-E1 osteoblast cultures. Matrix Biol 25: 135-148.

Archambault JM, Jelinsky SA, Lake SP, Hill AA, Glaser DL, Soslowsky LJ (2007) Rat supraspinatus tendon expresses cartilage markers with overuse. J Orthop Res 25: 617-624.

Ark JW, Flock TJ, Flatow EL, Bigliani LU (1992) Arthroscopic treatment of calcific tendinitis of the shoulder. Arthroscopy 8: 183-188.

Bosworth BM (1941) Calcium deposits in the shoulder and subacromial bursitis: a survey of 12,122 shoulders. JAMA 116: 2477-2482.

Brown H, Ehrlich HP, Newberne PM, Kiyoizumi T (1986). Para osteo arthropathy - ectopic ossification of healing tendon about the rodent ankle joint: histologic and type V collagen changes. Proc Soc Exp Biol Med 183: 214-220.

Cheung HS, Halverson PB, McCarty DJ (1981) Release of collagenase neutral protease, and prostaglandins from cultured mammalian synovial cells by hydroxyapatite and calcium pyrophosphate dihydrate crystals. Arthritis Rheum 24: 1338-1344.

Colnot C, Thompson Z, Miclau T, Werb Z, Helms JA (2003) Altered fracture repair in the absence of MMP9. Development 130: 4123-4133.

Cook IL, Purdam CR (2009) Is tendon pathology a continuum? A pathology model to explain the clinical presentation of load-induced tendinopathy. Br J Sports Med 43: 409-416.

De Palma AF, Kruper JS (1961) Long term study of shoulder joints afflicted with and treated for calcific tendinitis. Clin Orthop 20: 61-72.

Fisher LW, Fedarko NS (2003) Six genes expressed in bones and teeth encode the current members of the SIBLING family of proteins. Connect Tissue Res 44: 33 40 .
Franzen A, Oldberg A, Solursh M (1989) Possible recruitment of osteoblastic precursor cells from hypertrophic chondrocytes during initial osteogenesis in cartilaginous limbs of young rats. Matrix 9: 261-265.

Garau G, Rittweger J, Mallarias P, Longo UG, Maffulli N (2008) Traumatic patellar tendinopathy. Disabil Rehabil 30: 1616-1620.

Gwilym SE, Watkins B, Cooper CD, Harvie P, Auplish S, Pollard TC, Rees JL, Carr AJ (2009) Genetic influences in the progression of tears of the rotator cuff. J Bone Joint Surg Br 91: 915-917.

Halverson PB (2003) Crystal deposition disease of the shoulder (including calcific tendonitis and milwaukee shoulder syndrome). Curr Rheumatol Rep 5: 244-247.

Harvie P, Pollard TC, Carr AJ (2007) Calcific tendinitis: Natural history and association with endocrine disorders J Shoulder Elbow Surg 16: 169-173.

Higashikawa F, Eboshida A, Yokosaki Y (2007) Enhanced biological activity of polymeric osteopontin. FEBS Lett 581: 2697-2701.

Iismaa SE, Mearns BM, Lorand L, Graham RM (2009) Transglutaminases and disease: lessons from genetically engineered mouse models and inherited disorders. Physiol Rev 89: 991-1023.

Jelinsky SA, Lake SP, Archambault JM, Soslowsky LJ (2008) Gene expression in rat supraspinatus tendon recovers from overuse with rest. Clin Orthop Relat Res 466: 1612-1617.

Johnson KA, van Etten D, Nanda N, Graham RM, Terkeltaub RA (2003) Distinct transglutaminase 2-independent and transglutaminase 2-dependent pathways mediate articular chondrocyte hypertrophy. J Biol Chem 278: 18824-18832.

Kaartinen MT, Pirhonen A, Linnala-Kankkunen A, Mäenpää PH (1999) Transglutaminase treated osteopontin exhibits increased collagen binding properties. J Biol Chem 274: 1729-1735.

Kaartinen MT, Murshed M, Karsenty G, McKee MD (2007) Osteopontin upregulation and polymerization by transglutaminase 2 in calcified arteries of Matrix Gla protein-deficient mice. J Histochem Cytochem 55: 375386.

Karousou E, Ronga M, Vigetti D, Passi A, Maffulli N (2008) Collagens, proteoglycans, MMP-2, MMP-9 and TIMPs in human achilles tendon rupture. Clin Orthop Relat Res 466: 1577-82.

Lakemeier S, Braun J, Efe T, Foelsch C, ArchontidouAprin E, Fuchs-Winkelmann S, Paletta JR, Schofer MD (2011) Expression of matrix metalloproteinases 1, 3, and 9 in differing extents of tendon retraction in the torn rotator cuff. Knee Surg Sports Traumatol Arthrosc (in press).

Lippmann RK (1961) Observation concerning the calcific cuff deposit. Clin Orthop 20:49-60.

Logan J, Edwards K, Saunders N (2009) Real-Time PCR In: Current Technology and Applications. Caister Academic Press, pp 7-22.

Longo UG, Fazio V, Poeta ML, Rabitti C, Franceschi F, Maffulli N, Denaro V (2010) Bilateral consecutive rupture of the quadriceps tendon in a man with BstUI polymorphism of the COL5A1 gene. Knee Surg Sports Traumatol Arthrosc 18: 514-518. 
Longo UG, Oliva F, Denaro V, Maffulli N (2008) Oxygen species and overuse tendinopathy in athletes. Disabil Rehabil 30: 1563-1571.

Lorand L, Graham RM (2003) Transglutaminases: crosslinking enzymes with pleiotropic functions. Nat Rev Mol Cell Biol 4: 140-156.

Maffulli N, Reaper J, Ewen SW, Waterston SW, Barrass V (2006) Chondral metaplasia in calcific insertional tendinopathy of the Achilles tendon Clin J Sport Med 16: 329-334.

Magra M, Maffulli N (2007) Genetics: does it play a role in tendinopathy? Clin J Sport Med 17: 231-233.

Magra M, Maffulli N (2008) Genetic aspects of tendinopathy. J Sci Med Sport 11: 243-247.

Mokone GG, Schwellnus MP, Noakes TD, Collins M (2006) The COL5A1 gene and Achilles tendon pathology. Scand J Med Sci Sports 16: 19-26.

Nakase T, Takeuchi E, Sugamoto K, Kaneko M, Tomita T, Myoui A, Uchiyama Y, Ochi T, Yoshikawa H (2000) Involvement of multinucleated giant cells synthesizing cathepsin $\mathrm{K}$ in calcified tendinitis of the rotator cuff tendons. Rheumatology (Oxford) 39: 1074-1077.

Nurminskaya M, Kaartinen MT (2006) Transglutaminases in mineralized tissues. Front Biosci 11: $1591-1606$.

Nurminskaya M, Magee C, Faverman L, Linsenmayer TF (2003) Chondrocyte-derived transglutaminase promotes maturation of preosteoblasts in periosteal bone. Dev Biol 263: 139-152.

Oliva F, Zocchi L, Codispoti A, Candi E, Celi M, Melino G, Maffulli N, Tarantino U (2009) Transglutaminases expression in human supraspinatus tendon ruptures and in mouse tendons Biochem Biophys Res Commun 20: 887-891.

Pufe T, Petersen WJ, Mentlein R, Tillmann BN (2005) The role of vasculature and angiogenesis for the pathogenesis of degenerative tendons disease. Scand J Med Sci Sports 15: 211-22.

Refior HJ, Krödel A, Melzer C (1987) Examination of the pathology of the rotator cuff. Arch Orthop Trauma Surg 106: 301-308.

Reinholt FP, Hultenby K, Oldberg A, Heinegård D (1990) Osteopontin - a possible anchor of osteoclasts to bone. Proc Nat Acad Sci 87: 4473-4475.

Rider CC, Mulloy B (2010) Bone morphogenetic protein and growth differentiation factor cytokine families and their protein antagonists. Biochem J 429: 1-12.

September AV, Schwellnus MP, Collins M (2007) Tendon and ligament injuries: the genetic component. $\mathrm{Br}$ J Sports Med 41: 241-246.

Sharma P, Maffulli N (2008) Tendinopathy and tendon injury: the future. Disabil Rehabil 30: 1733-1745.

Sharma P, Maffulli N (2005) Tendon injury and tendinopathy: healing and repair. J Bone Joint Surg Am 87: $187-202$

Steinbrocker O (1972) The Painful Shoulder. In: Arthritis and Allied Conditions (Hollander JE, ed), Lea and Febiger, Philadelphia, pp 1461-1469.

Steitz SA, Speer MY, McKee MD, Liaw L, Almeida M, Yang H, Giachelli CM (2002) Osteopontin inhibits mineral deposition and promotes regression of ectopic calcification. Am J Pathol 161: 2035-2046.

Stephens M, Kwan AP, Bayliss MT, Archer CW (1992) Human articular surface chondrocytes initiate alkaline phosphatase and type $\mathrm{X}$ collagen synthesis in suspension culture. J Cell Sci 103: 1111-1116.

Sweet HO, Green MC (1981) Progressive ankylosis, a new skeletal mutation in the mouse. J Hered 72: 87-93.

Takeuchi E, Sugamoto K, Nakase T, Miyamoto T, Kaneko M, Tomita T, Myoui A, Ochi T, Yoshikawa H (2001) Localization and expression of osteopontin in the rotator cuff tendons in patients with calcifying tendinitis. Virchows Arch 438: 612-617.

Uthoff HK (1975) Calcifying tendinitis an active cell mediated calcification. Virchows Arch Pathol Anat 366: 51-58.

Uthoff HK (1997) Anatomopathology of calcifying tendinitis of the cuff. In: The cuff (Gazielly DF, Gleyze P, Thomas T, eds). Elsevier, Paris, pp 144-147.

Uthoff HK, Loehr JW (1997) Calcific tendinopathy of the rotator cuff: pathogenesis, diagnosis, and management. J Am Acad Orthop Surg 5: 183-191.

Yee Lui PP, Wong YM, Rui YF, Lee YW, Chan LS, Chan KM (2011) Expression of chondro-osteogenic BMPs in ossified failed tendon healing model of tendinopathy. J Orthop Res 29: 816-821.

Welfling J, Kahn MF, Desroy M, Paolaggi JB, de Seze S (1965) Calcifications of the shoulder. II. The disease of multiple tendinous calcifications. Rev Rhum Mal Osteoartic 32: 325-334.

Wu X, Shi W, Cao X (2007) Multiplicity of BMP signaling in skeletal development. Ann N Y Acad Sci 1116: 29-49.

Zafar MS, Mahmood A, Maffulli N (2009) Basic science and clinical aspects of Achilles tendinopathy. Sports Med Arthrosc 17: 190-197.

Zaka R, Stokes D, Dion AS, Kusnierz A, Han F, Williams CJ (2006) P5L mutation in Ank results in an increase in extracellular inorganic pyrophosphate during proliferation and nonmineralizing hypertrophy in stably transduced ATDC5 cells. Arthritis Res Ther 8: 1-13.

\section{Discussion with Reviewers}

Reviewer I: I would expect agarose gel electrophoresis data for visual demonstration of the data.

Authors: We now provide the PCR performed on the samples obtained from two of the ten patients evaluated, for whom we still had enough RNA to perform the analysis. Since end-point PCR is not able to provide a precise quantification, especially if a plateau is reached, we performed experiments at 25, 30, 35 cycles to detect possible differences. A description of the methodology, including the primers used, follows below. RNA and retrotranscription was performed as described for quantitative PCR. Qualitative PCR was performed using $30 \mathrm{ng}$ of cDNA as template, in a final volume of $25 \mu \mathrm{L}$, in buffer containing $1.5 \mathrm{mM} \mathrm{MgCl}_{2}$ and $150 \mathrm{nM}$ of forward and reverse primers. For tTG2, Osteopontin, 
and Cathepsin $\mathrm{K}$ the primers employed were the same as shown in Table 1, giving a PCR product of 153, 113 and 152 bp respectively. For BMP4 and BMP6 we designed the following primers, localised in different exons, giving a PCR product of 348 and 141 bp:

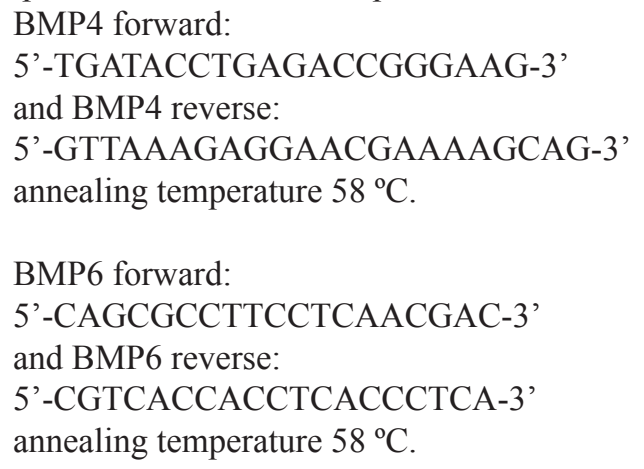

Preliminary experiments conducted at various cycles allowed us to identify a range in which we were able to observe differences among the samples before a plateau was reached. For this reason, amplifications were performed for 35 cycles except for GAPDH, in which 30 cycles were used (Fig. 4).

Reviewer I: Why did you not select TGF $\beta-1,2,3$ that are usually involved in osteogenesis?

Authors: We agree that TGF $\beta$ is usually involved in osteogenesis, a process markedly different from the production of calcifications observed in calcific tendinopathy (see below). Although we agree that it may be useful to perform an analysis of the expression of these genes, the scarcity of the material obtained obliged us to select those that were assessed. The collection of further selected samples will be necessary to evaluate other possible genes involved in the pathogenesis.

Reviewer I: What is the role of inflammation in calcific tendinitis and how does that correlate with their findings? Authors: Inflammatory cells and vessels are notably absent during the formative phase. Also, in the resting phase, fibrocollagenous tissue borders the foci of calcification without evidence of inflammation, thereby indicating termination of deposition (Archer et al., 1993). Typical cells of inflammation have been detected during the resorptive phase. Specifically, Nakase et al. clarified the nature of the multinucleated cells located near the calcium deposits. These were positive for cathepsin $\mathrm{K}$ protein and mRNA, and had a typical osteoclast phenotype. The same research group later detected osteopontin only in the cells adjacent to the calcified area, identifying, morphologically, two distinct types of osteopontin positive cells, i.e., mononuclear fibroblastic cells and round-shaped multinuclear cells (Nakase et al., 2000; Takeuchi et al., 2001 , text references). Other proteins or cells typical of the inflammation cascade still remain to be investigated in the process of calcific tendinopathy.

Reviewer I: Is calcific tendinitis similar to heterotopic ossification?

Authors: Heterotopic ossification is a common phenomenon after spinal cord injury, head injury, neurological disorders, burns and other trauma, and joint arthroplasty. Periarticular ossifications after shoulder surgery have been known to occur since the 19th century, at an incidence of up to 27 $\%$. After arthroscopic and minimally invasive shoulder surgical procedures were introduced and came into broad use, reports about heterotopic ossification became rare (Kircher et al., 2007). Heterotopic ossification is, by definition, the formation of bone within soft tissue. It is generally assumed that primitive mesenchymal cells stimulated by, for example, surgical trauma differentiate into osteoblastic cells, and produce osteoid that is finally mineralised and transformed into bone tissue. (Chalmers et al., 1975). The main feature of the calcific tendinopathy is the calcium deposits inside the rotator cuff tendon and not in the periarticular soft tissue such as capsule, muscles and ligaments, with no apparent concomitant cause.

Reviewer I: Can the authors speculate the potential role of primary myoblasts in calcific tendinitis? It is known that they play an important role in bone regeneration and fracture healing!

Authors: To our knowledge, primary myoblasts have not been detected around the calcium deposits in calcific tendinopathy. In the literature, several cells have been found in the various stage of the condition. The precalcific stage is characterised by metaplasia of the tendinous tissue into fibrocartilage. Separated by chondrocytes and fibrocartilaginous tissue septae, calcium crystals are deposited primarily in matrix vesicles that coalesce to form large foci of calcification (Uhthoff and Loehr, 1997, text reference).

The formative phase is characterised by multifocal calcific deposits, separated by fibrocollagenous tissue or fibrocartilage. The latter consists of easily distinguishable chondrocyte-like cells, within a matrix showing various degrees of metachromasia. (Archer et al., 1993). Young mesenchymal cells, epithelioid cells, leukocytes, lymphocytes, macrophages, and multinucleated giant cells then surround the deposits in an attempt to phagocytise them during the resorptive phase. The last phase is the post-calcific stage. Granulation tissue with young fibroblast and newly formed capillaries can be found around the calcification, in contrast with well-formed scars with vascular channels and maturing fibroblast following the long axis of the tendon fibres (Uhthoff and Loehr, 1997, text reference).

Reviewer II: What was the power of the statistical comparisons? I would expect that there is significant variation between samples, and $n=10$ may be insufficient to pick up differences.

Authors: We agree that the number of patients is limited, but it is very difficult to find a large number of patients with similar clinical features in a limited period of time. Given the small number of samples, the power of the statistical comparisons was below 0.800 ( 0.680 for BMP4, 0.753 for BMP6, but lower for collagen $\mathrm{V}$, about 0.430 ). With 10 patients, this study has a power of 0.80 (at least) of demonstrating a 0.3 difference at a two-sided 0.05 significance level. 
Reviewer II: In the supraspinatus tendon, expression of cartilage specific genes may be due to increased compression. Is it possible that this cartilage forms due to compression and is then mineralised, in a fashion similar to what has been described for endochondral ossification? A simplified time course of gene expression changes in that case may look something like: SOX9 -> collagen II -> collagen X -> Runx2 - > BMP-2 -> osteocalcin.

Authors: We agree that more genes should be investigated to increase our knowledge of the obscure physiopathology of this condition. However, the quantity of RNA extracted from the biopsy samples prevented us from performing further analysis. In addition, collagen X mRNA levels were below the limit of detection.

Reviewer II: My biggest concern with the interpretation of the data in relation to pathogenesis of the condition is with the timing of analysis. As the samples were all taken 6 months after symptoms appeared, the "snapshot" of gene expression changes shown here only captures the late stages of the disease. A time-course, or an analysis at earlier stages of the disease, would help elucidate the mechanisms of action.
Authors: We agree with this comment, but unfortunately, patients may be pain-free or mildly symptomatic, and often the pain is associated with resorption of the calcific deposits. Moreover, four different clinical presentations have been described, not linked with first deposition of calcium (Faure and Daculsi, 1983). Unfortunately, it is very unlikely that we would have been able to obtain biopsies at the precise moment of the pathologic calcium deposition.

\section{Additional References}

Archer RS, Bayley JI, Archer CW, Ali SY (1993) Cell and matrix changes associated with pathological calcification of the human rotator cuff tendons. J Anat 182: $1-12$.

Chalmers J, Gray DH, Rush J (1975) Observations on the induction of bone in soft tissues. J Bone Joint Surg Br 57: 36-45.

Faure G, Daculsi G (1983) Calcified tendonitis: a review. Ann Rheum Dis 42: 49-53.

Kircher J, Martinek V, Mittelmeier W (2007) Heterotopic ossification after minimally invasive rotator cuff repair. Arthroscopy 23: 1359 e1-3. 